\title{
A Case of Primary Hydatid Disease (Echinococcus) of the Fallopian Tube.*
}

\author{
By T. W. EDen, M.D., M.R.C.P., Assistant Obstetric Physician, \\ Charing Cross Hospital; Physician to In-patients, Chelsea \\ Hospital for Women; Physician to Out-patients, Queen \\ Charlotte's Lying-in Hospital.
}

THE female pelvic organs are but rarely the localities chosen for the deposition and development of the ova of the Tænia echinococcus. They not uncommonly become involved in extensive hydatid growths, developing primarily in the liver or other abdominal organs, but they are rarely the localities primarily affected. The ovary and Fallopian tube are among the last sites in the whole body selected by these parasites, and it is on account of the extreme rarity of the condition that the following case is recorded.

Mrs. E., age 40, was admitted to the Chelsea Hospital for women under my care on September 4th, 1903. She had been seen by me in the out-patient department in the previous July, where she came complaining of pain in the small of the back and in the left side, with troublesome palpitations of many years standing. Her menstrual periods were regular and the loss moderate in amount, but she habitually suffered severe pain during the whole time in the hypogastric and sacral regions. She had no vaginal discharge, and was in good general health. Although married for 13 years she had never been pregnant.

On local examination (July, 1903) a small, tense cyst was found in the pouch of Douglas, firmly adherent to surrounding structures, and counected by an easily palpated pedicle with the right cornu of the uterus. On rectal examination its posterior wall was felt to be of almost stony hardness, and the case was diagnosed as being probably a dermoid cyst of the right ovary. Its removal was advised, but as the Hospital was about to be closed for the annual cleaning, the operation was postponed until September.

On the patient's admission on September 4th, her condition was practically unchanged in all respects. The operation was performed on September 10th. After opening the abdomen the swelling was easily defined, as no adhesions had formed except in its immediate neighbourhood. The swelling itself was densely adherent, and on exposing it by means of retractors, its wall was seen to be of a dull

* Read at a meeting of the Obstetrical Society of London, June 1st, 1904. 
yellow colour and of very dense appearance, not unlike an ovarian dermoid with cartilaginous walls. Much time and care were expended in separating the unusually strong and resistant adhesions, some of which required ligature. The tumour ruptured in the manipulations, revealing its true nature, for large numbers of loose, thin-walled, cystic structures escaped, easily recognisable as hydatid vesicles, accompanied by loose membrane and a scanty amount of thin fluid. The tumour was emptied as far as possible and the loose vesicles and membrane carefully removed from the peritoneal cavity. The remaining adhesions were then separated, a good pedicle was obtained, and treated in the usual manner by transfixion and ligature. There was a good deal of oozing from the tumour-bed, but this was all controlled by pressure with hot sponges. The structures removed were the appendages of the right side; the left appendages were involved in adhesions apparently as dense as those surrounding the tumour. There was, however, no enlargement either of the tube or ovary, and as separation of the adhesions would in all probability have involved the removal of the appendages it was considered better to leave them undisturbed. No other swelling could be felt in the abdominal cavity, and the remaining viscera appeared to be quite free from hydatid disease, so far as could be determined by palpation. No drain was required, and the abdomen was closed in the usual manner, in three layers.*

Up to this time the tumour was believed to be ovarian, but careful examination by the Pathologist to the Hospital (Dr. Taylor) demonstrated its tubal character.

Description of the specimen. The specimen consists of the right uterine appendages including the ovary, the Fallopian tube, and the meso-salpinx. The ovary is of normal size, its surface being rough and showing tags of torn adhesions. On dividing the ovary it is seen to contain two small corpora lutea in the stage of retrogression, one abortive follicle containing blood, and one small cyst lined with a smooth membrane. The organ was obviously functionally active when removed. The meso-salpinx measures one inch in greatest vertical diameter; it is a little thickened, and its peritoneal surfaces are roughened from adhesions. The usual transparency of this portion of the broad ligament is lost, so that the condition of the parovarium cannot be made out by inspection.

The Fallopian tube measures 4 inches from the divided tube to

* Convalescence was a little delayed by the formation of a small hromatoma in the abdominal wound, but the patient left the Hospital well in a month. 


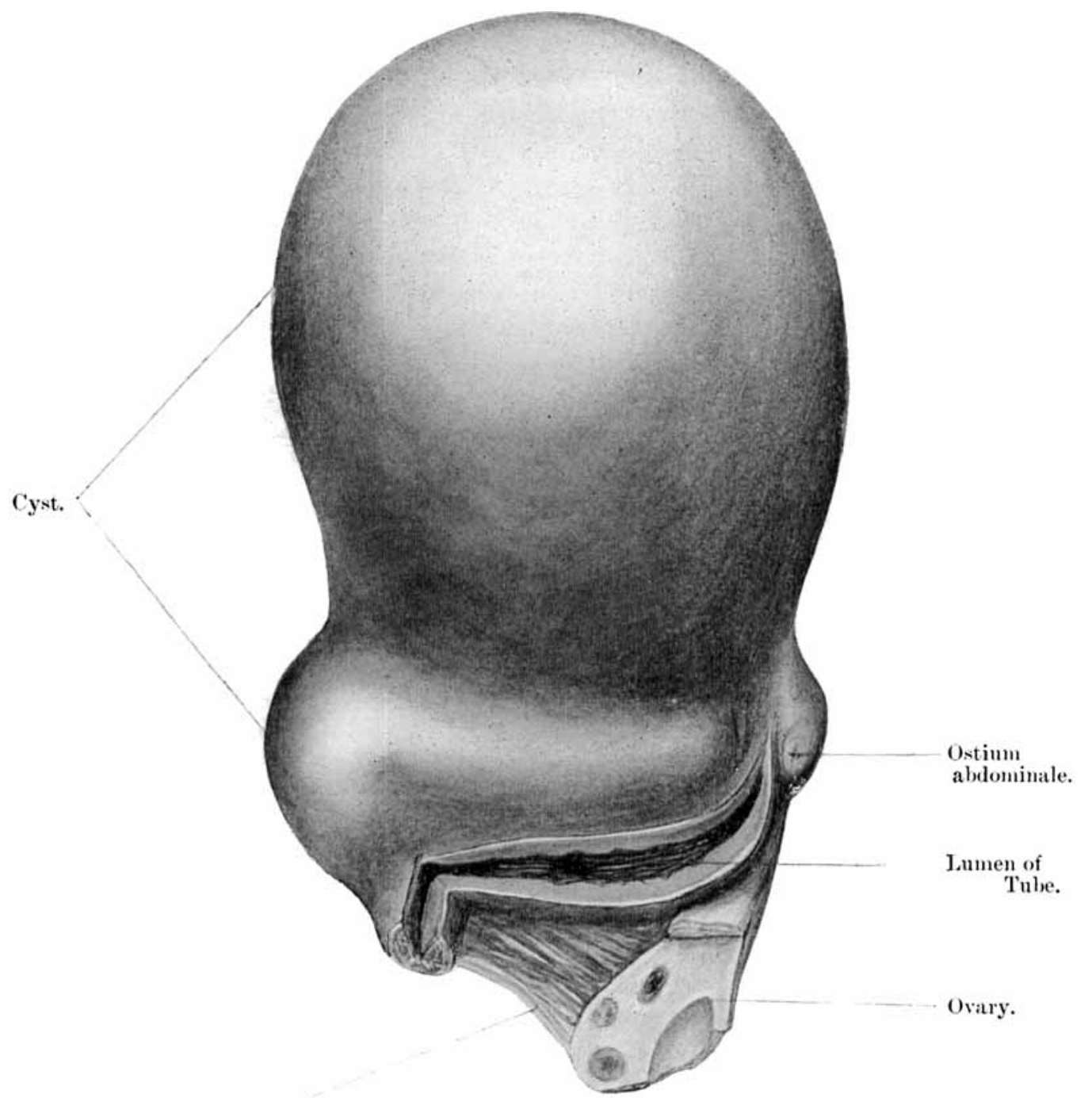

Meso-Salpinx.

Fig. 1.-Hydatid Cyst (Echinococcus) of the Fallopian Tube. 

the abdominal ostium. The inner third is not much altered in naked-eye characters. With the upper border of the outer two thirds is closely incorporated a cyst of considerable size; this cavity was at first regarded as the dilated lumen of the tube, and the hydatids were considered to occupy that portion of the canal of the tube. In fact this was the description of the specimen first sent in to the Society in this paper, but further examination proved it to be erroneous, and by the courtesy of the Senior Hon. Sec., I have been allowed to correct the error. As will be seen from the drawing (Fig. 1) the tubal caual is intact, and has been laid open, running apparently in the lower wall of the cyst. There is no communication whatever between the tubal canal and the cavity of the cyst, and it was owing to the failure to demonstrate this connection that the error in description was discovered. The union of the cyst wall with the upper wall of the tube is a firm organic union, and not the result of adhesions.

The abdominal ostium of the tube is sealed, but its position is clearly indicated in the specimen by a dimple and a small tag which may represent a single atrophied fimbria. The surface of all parts of the specimen is roughened and shows many tags of adhesions.

The cyst, which is oval in shape, rises steeply from the upper wall of the tube, and is firmly incorporated with it from the junction of the inner and middle thirds nearly to the abdominal ostium. It measures $4 \frac{1}{2} \mathrm{in}$. in vertical, $3 \mathrm{in}$. in transverse, and $2 \frac{1}{4} \mathrm{in}$. in anteroposterior diameter. The wall varies in thickness from $1 / 18$ to $\frac{1}{4}$ of an inch, being on an average about $\frac{1}{8}$ of an inch. It contains but a single cavity, the inner wall is smooth and polished, the hydatid membrane having been completely detached.

Microscopic details. Examination of the fluid obtained from the hydatid vesicles shows large numbers of typical brood-capsules, and free hooklets. The detached membrane is lamellar in character and represents the outer cuticular layer of the cyst. Sections of the wall of the tube taken from the dilated portion show that little of the normal structure remains, the greater part consisting of stratified layers of hydatid membrane showing the characteristic pectinate markings.

The diagnosis of the nature of the tubal cyst is thus fully established; but its mode of origin is not so simple and presents some points of interest. Two points are fairly clear : Firstly, the hydatid ova were not deposited in the lumen of the tube, nor has the resulting cyst involved the lumen in its further development. Secondly, the 
union of the cyst with the wall of the tube is so intimate that it cannot be possible that free peritoneal hydatids have become adherent to the tube and have developed in that position. Further, there is no evidence of any other abdominal organ having been infested with the parasite. This point is worth consideration because, in the view of Lawson Tait pelvic hydatids always arise secondarily to rupture and escape of hydatid vesicles from another abdominal organusually the liver. The most probable explanation appears to be that the ova were deposited in the tissues of the upper wall of the tube, and their development in that position was sufficiently slow and gradual to avoid rupture either into the peritoneal cavity or the tubal canal. Inasmuch as the sub-peritoneal cellular tissue is the favourite abdominal location for hydatids, it seems further reasonable to surmise that in this case ova were deposited beneath the peritoneal covering of the tube, and that they continued to develope in that position. From the long duration of the patient's symptoms and the unusual density of the adhesions met with at the operation, it is clear that the disease was of long standing-probably of many years,-and the microscopic recognition of a peritoneal investment after so long an interval is, of course, impossible.

Regarding the source of the parasitic infestment, I can give no information. The patient had lived all her life in London or its immediate neighbourhood, and she had never kept a dog or cat or any other pet animal in her life. The ova must have been taken in with some article of food.

The first writer, who endeavoured to collect information about pelvic hydatids appears to have been Villard, who published in the Annales de Gynécologie for 1878 a paper entitled "Considerations cliniques sur les kystes hydatidiques du petit basin chez la femme." In this paper he collected 12 cases published since 1817, and added a personal observation of his own. Following him Freund, ${ }^{1}$ in 1885, published 18 fresh cases observed by himself, and to him is due the credit of laying the foundation of our knowledge of the subject. Since Villard's paper was published numerous additional cases have been recorded, and these have been collected by Doléris, ${ }^{2}$ who, in 1896, brought up the total to 70 cases, including those previously recorded. Pelvic hydatids, as a complication of pregnancy and labour have recently been discussed by a Hungarian writer, Franta, ${ }^{3}$

1. "Gynäkologische Klinik," 1885, p. 302.

2. "La Gynécologie," 1896, p. 97.

3. Boubele, Mëchozilové Teilotenstoi za Porodu, a v. Sestinedeli. 
in an important monograph of 250 pages. But it may be said that these researches throw no light upon the conditions which determine the locality which the hydatid ova select for their development.

Pelvic hydatids appear to find their primary lodgment in the great majority of cases beneath the peritoneum in the pelvic cellular tissue of the pouch of Douglas. Here they burrow in all directions and come into relation with the uterus, bladder, rectum, ovary, and Fallopian tubes. No case has yet been recorded of the primary lodgment of hydatids in the uterine cavity or the uterine walls. ${ }^{4}$ Several cases are known where hydatids have invaded the hollow pelvic viscera by perforation of their walls, but that is obviously a different condition, and must not be confused with cases of primary lodgment.

In the Fallopian tube and ovary, primary hydatid disease is extremely rare, and I have thought that it might be useful to look through the literature with the object of finding such cases if they existed, and of examining the evidence in favour of their primary origin in these organs.

Text-books, I was not surprised to find, contradict one-another consistently upon the subject. In the last edition of his text-book on "Tumours," Mr. Bland-Sutton says that no case of primary hydatid disease of the ovary has been recorded, and only one case in the Fallopian tube, i.e., the case of Doléris. Veit's "Handbuch der Gynäkologie" states, on the other hand, that a case of primary echinococcus of the ovary was recorded by Péan in 1895. Martin, in his monograph “ Die Krankheiten der Eileiter," published in 1895, makes no mention of echinococcus of the tube. Griffith, in the " System of Gynæcology," edited by Allbutt and Playfair, says there is "grave doubt whether any of the cases so recorded are really hydatids of the ovary."

My search through the literature has convinced me that there was on record, previous to my own, one case of undoubted primary hydatid disease of the ovary, and one of the Fallopian tube, and I now give short abstracts of these cases as recorded by the authors.

Péan's account of his case is so brief that it may be transcribed verbatim. 5

4. Since this paper was written an Inaugural Dissertation of the University of Amsterdam by J. de Vries has appeared on the subject of Echinococcus of the Uterus. The author records an original observation of his own, and claims to have found in the literature seven other cases of apparently primary uterine hydatids. The original paper I was unable to read, and the only abstract which I have found was very cursory (Monats. fuir Geburts. und Gynákol., March, 1904), so that I am unable to do more than call attention to de Vries' paper.

5. "Diagnostique et Traitement des Tumeurs de l'Abdomen," Vol. III., p. 671. 
" $\mathrm{C}_{\mathrm{ASE}}$ 98. Hydatid cyst of right ovary; coliotomy; recovery. M.O., Spaniard, 19 years old, submitted to operation June 12th, 1888. Brunette, pale, very emaciated. Menstruated first at age of 11 ; not married. Commencement of trouble 10 years ago in the right side of abdomen. No pain. Four months before operation capillary puncture had yielded 6 litres of fluid. Abdomen distended to umbilicus.

"Operation. Abdominal wall incised from pubes to umbilicus; no ascites or adhesions. Cyst wall whitish, moderately thick. On puncture 8 litres of limpid fluid mixed with hydatids. Incision of the cyst enabled us to withdraw a considerable quantity of daughter cysts, and to determine that the cyst originated in the ovary and had become prolonged into the broad ligament. This was clamped, ligatured in two parts, and returned after the excision of the tumour. Duration 15 minutes ; good recovery ; no recurrence."

It is unfortunate that a more detailed description of the cyst after removal was not given, nor any note made of the absence of hydatid growths in other organs. But the authority of Prof. Péan is unimpeachable, and I am certainly prepared to accept this case as the only undoubted instance recorded of primary hydatid disease of the ovary. Very many cases are on record in which the ovary was involved in extensive pelvic hydatids, but in such instances demonstration of the organ primarily affected is impracticable, and they need not be further referred to.

The previous case of hydatid disease of the Fallopian tube was recorded in full detail by Doléris in 1896. The following is an abstract of his description :-

"M.J., age 36, the daughter of a butcher, was married at the age of 24 , to a man of the same occupation as her father. She was not personally brought much in contact with animals. Towards the end of the first year of her married life she began to suffer from attacks of abdominal pain which often necessitated her staying in bed. At first these attacks coincided with the periods, later they became quite irregular. After a few months constipation and dysuria appeared. An abdominal tumour was discovered in 1888, and thought to be a fibroid; she was treated with ergot for many months, and got much thinner, the monthly loss being diminished. During the last 5-6 years the tumour has grown rapidly. She has never been pregnant.

"She was seen by Doléris in September, 1895. He found the cervix small and firm, and displaced upwards and forwards behind the symphysis. The body could not be felt. The pouch of Douglas was depressed towards the vagina and contained a firm, regular 
tumour. Per abdomen a nodular tumour was felt, extending above the umbilicus nearly to the epigastrium, and about the size of a

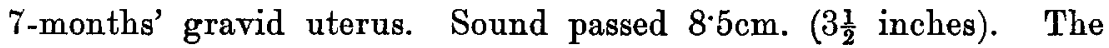
diagnosis was a multi-nodular fibroid.

" On March 24th, 1896, the patient was submitted to operation. The tumour was found to consist of the two Fallopian tubes

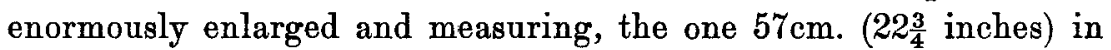

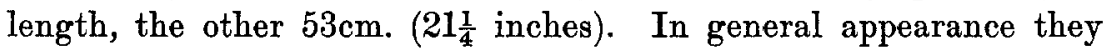
resembled large intestine, with thickened walls, and were irregularly distended in places. The convolutions of the tumours were intimately adherent to one another by broad surfaces. The cavity was full of hydatid capsules. On the omentum were some small cysts resembling dead hydatids, but there was no other trace of tumour in any of the abdominal organs.

"After removal the tumours weighed 2 kilos. The walls varied in thickness, and were pearly-white in colour, and almost transparent in places. Both tubes were distended in the greater part of their extent, the right to within 1 inch the left to within $\frac{1}{3}$ inch of the uterus. The ovaries, though adherent, were normal in appearance."

Doléris's description of the parts removed leaves something to be desired, and the illustration published with his paper represent the tubal swellings intact. But the author clearly regarded the condition as the development of hydatid vesicles within the tubal canal, so that the case differs considerably from that here recorded. 